\title{
Euthanasia: discussion before decision
}

$\mathrm{T}$ he fact that terminally ill patients in Quebec now have a legal right to physician-led euthanasia doesn't mean doctors in the province are eager to broach the subject. But it does mean they can no longer avoid the topic if a patient brings it up.

"Before, it was easier to say to a patient that we can't really discuss that because it's not legal, so let's talk about something else, whereas now you won't be able to say that," says Dr. Benjamin Schiff, director of in-hospital family physicians at St. Mary's Hospital Center in Montréal. "You will have to address it."

Schiff and Dr. Isabelle Leblanc, assistant director of physician apprenticeship at McGill University in Montréal, discussed this and other issues surrounding Quebec's new end-of-life legislation in a presentation called "Whose death is it anyway? Legalized euthanasia and end-of-life" at the recent Family Medicine Forum 2014, held in Québec City.

"All institutions have to be able to offer that service to patients, which is going to be very difficult because there is a lot of resistance," says Leblanc. "It's a big shift in the way we practise medicine, and a lot of people are uncomfortable with it. Some people are comfortable with the idea but not necessarily with actually doing it."

Under the new law, no physician can be forced to hasten a patient's

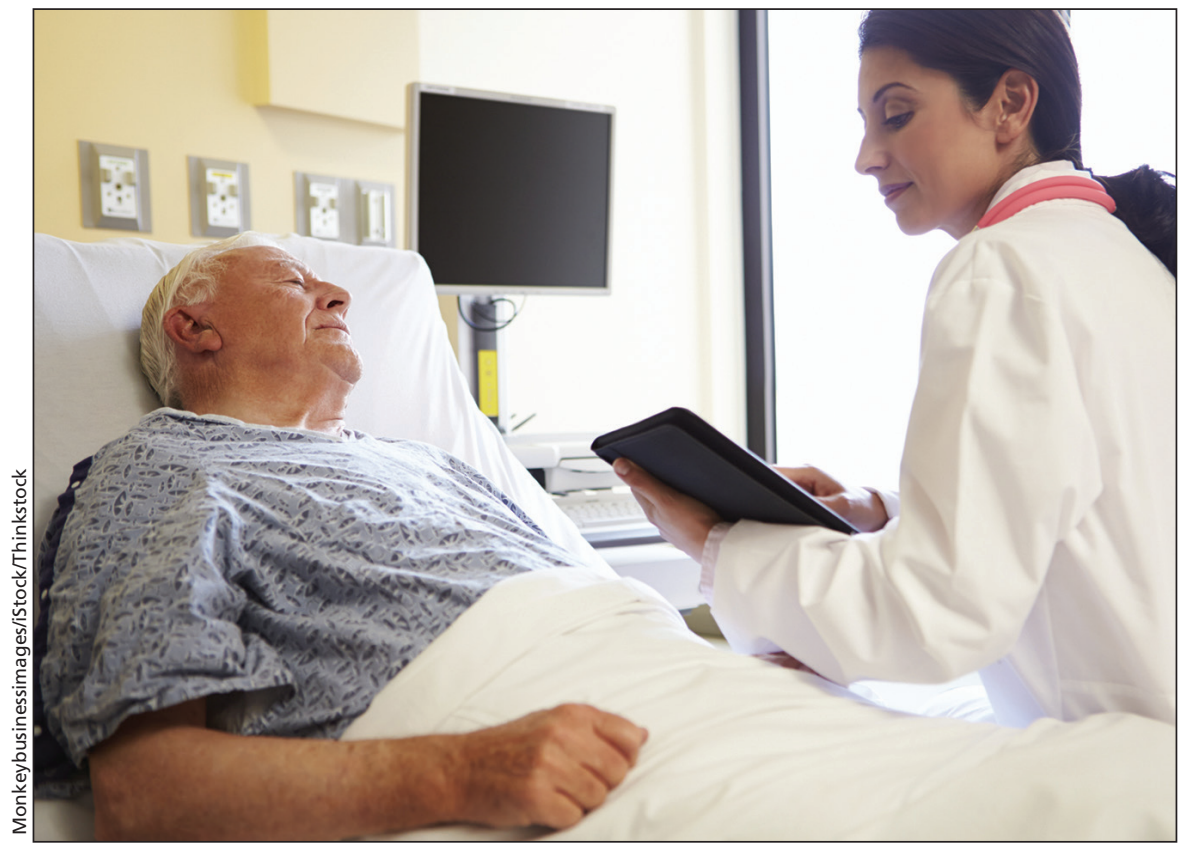

Whether legal or illegal, a request for euthanasia is the beginning of a conversation, not a decision.

active participation of physicians, who many see as authority figures, in administering the lethal dose of medication will influence whether patients feel comfortable changing their minds. Leblanc notes that, in areas where physicians instead write prescriptions for drugs that people can take at home to end their lives, many times the drugs are never actually used.

"It gives the patient a choice until the very end," says Leblanc. "One of the big issues with euthanasia is that it's final."

\section{Whether it's legal or not legal, it's still an expression that there is some level of suffering."}

death, but the treating physician is expected to perform the task. To avoid doing so, a physician must consult the chief of his or her institution to find a solution. It is possible, then, that doctors may earn reputations for refusing to participate actively in euthanasia or, conversely, for participating too often.

"That is where physicians have some concerns," says Leblanc. "Does it mean people are going to be keeping tabs?"

Another concern is whether the
Debate over the underlying ethical principles of actively ending a patient's life hasn't changed much in recent years, says Schiff. Concerns being raised about how legalizing euthanasia will affect medicine and society are similar to those raised 20 years ago. What has changed, however, is the availability of information from areas in Europe and the United States where physicians are already involved in some form of euthanasia or assisted-suicide.
"Rather than looking at the hypothetical, you can look at what actually has happened, so to a certain extent the discussion has gone a little bit away from only the issues of principles and a little bit more toward the issues around consequences," says Schiff. "That's a little bit easier because that's something you can actually measure."

Still, many practical questions about implementation remain. Will all institutions have to offer the service in-house or can partnerships be formed? Will private clinics be created to provide euthanasia? Can nonphysicians be trained to perform the procedure?

What's certain, however, is that the decision to end a life should never be rushed or taken lightly, says Schiff. Requests for euthanasia from patients must be explored thoroughly to find the root of the suffering. How did the patient come to this decision? Has their medical care been inadequate? Is there really no other option?

"Whether it's legal or not legal, it's still a cry for help, an expression that there is some level of suffering," says Schiff. "So that's where the conversation starts." - Roger Collier, CMAJ 